Original Research Article

\title{
Effects of maternal hemoglobin on fetal birth weight
}

\author{
N Pavan Kumar ${ }^{1}$, Jayalakshmi Pabbati ${ }^{2}$ \\ ${ }^{1}$ Dr. N. Pavan Kumar, Assistant Professor, Department of Pediatrics, MediCiti Institute of Medical Sciences, Medchal \\ ${ }^{2}$ Dr. Jayalakshmi, Assistant Professor, Department of Pediatrics, Medchal Mandal, Medchal District, Hyderabad, \\ Ghanpur, Telangana 501401, India.
}

Address for Correspondence: Dr. Jayalakshmi, Assistant Professor, Department of Pediatrics, MediCiti Institute of Medical Sciences, Medchal. Email id:jayalakshmipaed@gmail.com

\begin{abstract}
Introduction: Anaemia is one of the main nutritional deficiency disorders affecting a large proportion of the population, not only in developing but also in industrialized countries. The high prevalence of iron and other micronutrient deficiencies among women before and during pregnancy in developing countries is of concern and maternal anaemia is still a cause of considerable perinatal mortality and morbidity. The improvement in the industrialized world is due largely to more effective diagnosis and treatment of anaemia. Aim of the study: To determine effect of maternal hemoglobin on fetal cord blood haemoglobin and birth weight, To find out relation between cord blood haemoglobin and maternal haemoglobin \& to find the relation of birth weight to maternal haemoglobin. Results: The prevalence of low birth weight among anemic mothers was $24 \%$. Total number of babies with cord blood hemoglobin < 16.8 gms\% in mild anemic mothers were $74(80.4 \%)$ moderate anemia were $43(79.6 \%)$ and in severely anemic mothers were $2(50 \%)$. The demographic data of patients were studied for the 3 groups (mild, moderate, severe according to WHO classification of anemia) The means of the continuous variables were compared between the two groups using analysis of variance ANOVA. The P value of $<0.05$ was considered statistically significant. Conclusion: In babies born to anemic mothers cord blood hemoglobin is low. Severity of maternal anemia is determinant of low birth weight. The proportion of low birth weight in babies born to severe anemic mothers were more when compared to mild and moderate anemia
\end{abstract}

Key words: Anemia, Birth weight, Haemoglobin, Cord blood

\section{Introduction}

Anaemia is one of the main nutritional deficiency disorders affecting a large proportion of the population, not only in developing but also in industrialized countries. In the developing countries, poverty, gender bias and lack of education about the importance of a balanced and iron-rich diet contribute to anaemia. The high prevalence of iron and other micronutrient deficiencies among women before and during pregnancy in developing countries is of concern and maternal anaemia is still a cause of considerable perinatal mortality and morbidity. The improvement in the industrialized world is due largely to more effective diagnosis and treatment of anaemia. According to WHO anemia is present when the hemoglobin percentage is less than $11 \mathrm{gm}$ per dl during pregnancy [1].

Anemia is classified into moderate, severe \& very severe as shown in the table below: Most common cause of anemia during pregnancy is iron deficiency. In addition to iron deficiency other causes of anemia are megaloblastic anemia, anemia caused by acute blood loss, anemia of inflammation or malignancy, acquired hemolytic anaemia, aplastic/ hypo plastic anemia and other hereditary causes like thalassemias, hemoglobinapathies, and hereditary hemolytic anaemia [2].

The modest fall in hemoglobin levels observed during pregnancy in healthy women not deficient in iron or folate is caused by a relatively greater expansion of plasma volume compared with the increase in hemoglobin mass and red cell volume. The disproportion between the rates at which plasma and erythrocytes are added to the maternal circulation is

Manuscript received: $4^{\text {th }}$ September 2016

Reviewed: $14^{\text {th }}$ September 2016

Author Corrected; $25^{\mathrm{h}}$ September 2016

Accepted for Publication: $7^{\text {th }}$ October 2016 
normally greatest during the second trimester. The resulting hemodilution results in physiological anemia of pregnancy [2]. During the puerperium, in the absence of excessive blood loss, hemoglobin concentration is not appreciably less than pre delivery. After the delivery the hemoglobin level fluctuates around the pre delivery value for a few days and then rises to the higher non pregnant level. The rate and magnitude of increase early in the puerperium is the result of the amount of hemoglobin added during pregnancy and the amount lost by blood loss at delivery and modified by a puerperal decrease in plasma volume. Effects of anemia in the baby are low birth weight and intrauterine growth retardation (this occurs because maternal anemia influences placental vascularisation by altering angiogenesis during early pregnancy) [3]. Effects of anemia on mother are preeclampsia and eclampsia, abruptio placenta, preterm labor, premature rupture of membranes, precipitate labor, post partum hemorrhage, cardiac failure in severe anemia, puerperal infection, deep vein thrombosis, and failure of lactation.

\begin{tabular}{|c|c|}
\hline Category (Anemia severity) & Hemoglobin Level (gm/d) \\
\hline Mild & $10-10.9$ \\
\hline Moderate & $7.1-9.9$ \\
\hline Severe & $4.1-7.0$ \\
\hline Very severe & $<4.0$ \\
\hline
\end{tabular}

- This study was undertaken to determine the effect of maternal hemoglobin on fetal cord blood haemoglobin and birth weight

\section{Material and Methods}

The Study was conducted with collaboration of Departments of Pediatrics and Obstetrics/Gynecology at MediCiti Institute of Medical Sciences (MIMS) from December 2011 to June 2013. Institutional Ethical committee approval was sought. An informed consent was obtained from all mothers willing to participate in the study.

Sample size - 150

Venous blood samples from the mother were taken at the time of delivery along with cord blood Hemoglobin from the blood samples were estimated by Cyanmeth Hemoglobin Method. Newborn weight was recorded by digital scale (corrected upto $10 \mathrm{~g}$ ). Gestational age assessment was done by New Ballards score in Departments of Pediatrics and Obstetrics/Gynecology, MIMS [4].

Inclusion criteria - all term babies born in this hospital with maternal hemoglobin $<11 \mathrm{~g} / \mathrm{dl}$

Exclusion criteria - Babies born to women having medical conditions known to influence fetal growth -

- Hypertensive disorder of pregnancy

- Cardiac failure, -Acute systemic infections or chronic infections

- Multiple pregnancy -Metabolic disorders like diabetes mellitus

- New borns with congenital anomalies

- Babies born outside the hospital

- Mothers with hemoglobin $\geq 11 \mathrm{~g} / \mathrm{dl}$.

\section{Results}

Total number of deliveries (normal and Caesarean section) during the period from December 2011 to June 2013 were 3210. After fulfilling inclusion and exclusion criteria 150 normal term babies with maternal hemoglobin $<11$ gms $\%$ were included in the study.

Statistical Analysis- The demographic data of patients were studied for the 3 groups (mild, moderate, and severe according to WHO classification of anemia)

Statistical analysis was done using STATA 11 software. Data was expressed as either mean \pm standard deviation or numbers and percentages. The means of the continuous variables were compared between the two groups using analysis of variance ANOVA. The $\mathrm{P}$ value of $<0.05$ was considered statistically significant. 
Out of 150 babies, $36(24 \%)$ babies were of low birth weight and $114(76 \%)$ normal weight $(\geq 2.5 \mathrm{~kg})$. Out of 150 mothers, $92(61.32 \%)$ had mild anemia and 54 (36\%) moderate anemia and $4(2.67 \%)$ had severe anemia.

Table-1: Frequency Distribution of babies according to cord blood hemoglobin

\begin{tabular}{|c|c|c|}
\hline Cord blood Hb in gm\% & No. Of babies $\mathbf{N}=(\mathbf{1 5 0})$ & \% \\
\hline$\geq 16.8$ & 31 & 20.67 \\
\hline$<16.8$ & 119 & 79.33 \\
\hline
\end{tabular}

- Low birth weight babies in mothers with mild anemia were 17 (18.5\%), moderate anemia $16(29.7 \%)$ and those with severe anemia are $3(75 \%)$

- Total number of babies with cord blood hemoglobin $<16.8$ gms\% in mild anemic mothers were $74(80.4 \%)$, moderate anemia were $43(79.6 \%)$ and in severely anemic mothers were $2(50 \%)$.

Table-2: Categorical Distribution of cord blood hemoglobin according to birth weight ( $\mathrm{N}=150)$

\begin{tabular}{|c|c|c|}
\hline Birth Weight & Cord Hb $(\mathbf{g m s} \%) \geq \mathbf{1 6 . 8}(\mathbf{n}=\mathbf{3 1})$ & Cord Hb $(\mathbf{g m s} \%)<\mathbf{1 6 . 8}(\mathbf{n}=\mathbf{1 1 9})$ \\
\hline$\geq 2.5$ & $23(74 \%)$ & $91(76.4 \%)$ \\
\hline$<2.5$ & $8(25.80 \%)$ & $28(23.5 \%)$ \\
\hline
\end{tabular}

Table-3: Assessment of Birth Weight according to maternal hemoglobin

\begin{tabular}{|c|c|c|}
\hline Groups & \multicolumn{2}{|c|}{ Birth Weight } \\
\cline { 2 - 3 } & Range & Mean \pm SD \\
\hline $\begin{array}{c}\text { Maternal Hemoglobin } \\
10-10.9 \text { gms\% (MILD) }\end{array}$ & $2.02-4.4$ & \\
\hline Maternal Hemoglobin & $1.6-3.8$ & $2.670 \pm .453$ \\
7.1-9.9 gms\%(MODERATE) & & $2.227 \pm .639$ \\
\hline Maternal Hemoglobin & $1.6-3.12$ \\
\hline 4.1-7.0 gms\%(SEVERE) & & \\
\hline Significance & F $=6.70, \mathrm{p}=0.0044$ (significant) \\
\hline
\end{tabular}

Table-4: Assessment of Cord Blood Hemoglobin according to maternal Anemia

\begin{tabular}{|c|c|c|}
\hline \multirow{2}{*}{ Groups } & \multicolumn{2}{|c|}{ Cord Blood Hemoglobin } \\
\cline { 2 - 3 } & Range & Mean \pm SD \\
\hline Maternal Hemoglobin & $7.6-19.5$ & $14.60 \pm 2.620$ \\
$10-10.9$ gms\%(MILD) & & $14.753 \pm 2.510$ \\
\hline Maternal Hemoglobin & $8.3-19.8$ \\
\hline 7.1-9.9 gms\%(MODERATE) & & $16.025 \pm 2.334$ \\
\hline Maternal Hemoglobin & $13.7-18.5$ & \\
\hline Significance & & \\
\hline
\end{tabular}

The proportion of low birth weight of babies born to mothers with severe anemia is significantly more when compared to babies born to mothers with mild anemia.

\section{Discussion}

Prevalence of anaemia in all the age groups is higher in India as compared to other developing countries. According to $\mathrm{WHO}$, the prevalence of anaemia in pregnancy in globally is around 55.9\%. In India incidence of anaemia in pregnancy has been noted as high as $33-89 \%$ [5]. It increases the maternal morbidity, fetal and neonatal mortality and morbidity significantly with 7-10 million children born with low birth weight each year. Margaret Balfour was credited as the first to draw the attention of anaemia in pregnancy in India [6]. Levy et al for example, observed that maternal anemia was an independent risk factor for preterm delivery and 
low birth weight [7]. Malhotra et al, observed that the mean birth weight was highest in babies with maternal haemoglobin concentration between 9.6 and $10.5 \mathrm{gm} \%$ [8].

This study examined the relationship between maternal anemia and cord blood haemoglobin and the influence of maternal anemia on birth weight.

The values of cord blood hemoglobin were lower than the normal cord blood hemoglobin values in all grades of severity of maternal anemia, however there was no significant change in cord blood hemoglobin with increasing severity of maternal anemia.

In our study there was positive relationship between severity of maternal anemia and low birth weight. The proportion of birth weight in newborn of mothers with severe anemia was significantly low when compared to newborns of mothers with mild and moderate anemia.

3 of $4(75 \%)$ babies born to mothers with severe anemia were low birth weight $(<2.5 \mathrm{~kg}) .16$ of $54(29 \%)$ babies born to mothers with moderate anemia are low birth weight. 17 of $92(18.4 \%)$ babies born to mothers with mild anemia were low birth weight.

Maternal hematological status and risk of low birth weight and preterm delivery was studied in Patan Hospital, Kathmandu, Nepal. In this case-control study, 1400 pregnant women who attended the hospital for antenatal care and delivery in the period 1994 to 1996 were included. Severe anemia (hematocrit $\leq 24 \%$ ) was associated with a significantly increased risk of low birth weight $(<2500 \mathrm{~g})$ and preterm delivery $(<37$ weeks gestation) [9].

In study of Nadia et al the newborn birth weight was affected by maternal anaemia' out of 50 newborns 35 babies born to mothers with mild anemia had mean birth weight of $3.1 \mathrm{Kg}, 11$ babies born to mothers with moderate anemia had mean birth weight of $2.7 \mathrm{~kg}$ and 4 babies born to mother with severe anemia the mean birth weight was $2.2 \mathrm{~kg}$ [10]. Hence in our study the relation of severity of maternal anemia with birth weight was similar to Nadia et al study.

The effect of maternal iron deficiency anemia on fetal growth was studied by Singla et al in 54 anaemic (haemoglobin $<11.0 \mathrm{~g} / \mathrm{dl}$ ) mothers. Twenty-two mothers served as controls (haemoglobin $\geq 11.0 \mathrm{~g} / \mathrm{dl}$ ). [11]
The birth weight, head circumference, chest circumference, mid-arm circumference, and crown heel length were significantly low in infants born to women with moderate (haemoglobin 6.1 to $8.5 \mathrm{~g} / \mathrm{dl}$ ) and severe anaemia (haemoglobin $\leq 6.0 \mathrm{~g} / \mathrm{dl}$ ), in comparison to infants born to non-anaemic women. In our study where only newborn weight was taken into account mothers with severe anemia have significantly lower birth weight babies.

Low birth weight in severely anemic mothers can be explained due increased levels of stress hormones, nor epinephrine, and cortisol.

\section{Conclusion}

1. In babies born to anemic mothers cord blood hemoglobin is low.

2. Severity of maternal anemia is determinant of low birth weight.

The proportion of low birth weight in babies born to severe anemic mothers were more when compared to mild and moderate anemia

\section{Funding: Nil, Conflict of interest: Nil Permission from IRB: Yes}

\section{References}

1. Hussein L Kidanto, Ingrid Mogren, Gunilla Lindmark, Siriel Massawe, Lennarth Nystrom, Risks for preterm delivery and low birth weight are independently increased by severity of maternal anaemia. February 2009, Vol. 99, No. 2 SAMJ

2. Gruenwald P: fetal 1 Growth and Development, Williams Obstetrics, 23e > Chapter 43.

3. Chandra S, Anil Kumar T Anemia: A Brief Overview Regards the Pregnant State. J Womens Health, Issues Care, 2014; 3:1.

4. Ballard JL, Khoury JC, Wedig K, Wang L, EilersWalsman BL, Lipp R. New Ballard Score, expanded to include extremely premature infants. J Pediatr. 1991 Sep; 119(3):417-23.

5. Sumithra Muthayya, Maternal nutrition \& low birth weight - what is really important? Division of Nutrition, St. John's Medical College \& Research Institute, St. John's National Academy of HealthSciences, Bangalore, India. Indian J Med Res 130, November 2009, pp 600-608. 
6. R.G. Viveki, A.B. Halappanavar, P.R. Vivek, S.B Halki, V.S. Maled, P.S. Deshpande, Prevalence of Anaemia and Its Epidemiological Determinants in Pregnant Women 2012, AJMS US National Library of Medicine enlisted journal).

7. Levy A, Fraser D, Katz M, Mazor M, Sheiner E., Maternal anemia during pregnancy is an independent risk factorfor low birthweight and preterm delivery. 2005; 122(2) : 182-186. International Journal of Gynaecology \& Obstetrics.

8. Malhotra M, Sharma JB, Batra S, Sharma S, Murthy NS, Arora R. Maternal and perinatal outcome in varying degrees of anemia. Int J Gynaecol Obstet. 2002 Nov;79(2):93-100.
9. Bondevik GT, Lie RT, Ulstein M, Kvåle G. Maternal hematological status and risk of low birth weight and preterm delivery in Nepal. Acta Obstet Gynecol Scand. 2001 May;80(5):402-8.

10. Dr.NadiaMudher Al-Hilli,The Effect of Maternal Anaemia on Cord Blood Haemoglobin\& Newborn Birth Weight,2010,Karbala Journal of Medicine, 2(8-9), 2010.

11. Singla PN, Tyagi M, Kumar A, Dash D, Shankar R. Fetal growth in maternal anaemia. J Trop Pediatr. 1997 Apr; 43(2):89-92.

\section{How to cite this article?}

N Pavan Kumar, Jayalakshmi Pabbati. Effects of maternal hemoglobin on fetal birth weight. Int. J PediatrRes.2016;3(10):749-753.doi:10.17511/ijpr.2016.i10.06 